\title{
Cloning and Characterization of Low-Molecular-Weight Glutenin Subunit Alleles from Chinese Wheat Landraces (Triticum aestivum L.)
}

\author{
Hongqi Si, ${ }^{1,2}$ Manli Zhao, ${ }^{1}$ Xin Zhang, ${ }^{1}$ Guoliang Yao, ${ }^{1}$ Genlou Sun, ${ }^{1,3}$ and Chuanxi Ma ${ }^{1,2}$ \\ ${ }^{1}$ School of Agronomy, Anhui Agricultural University, Hefei 230036, China \\ ${ }^{2}$ Key Laboratory of Wheat Biology and Genetic Improvement on South Yellow \& Huai River Valley, \\ Ministry of Agriculture, Hefei 230036, China \\ ${ }^{3}$ Biology Department, Saint Mary's University, Halifax, NS, Canada B3H 3C3
}

Correspondence should be addressed to Genlou Sun; genlou.sun@smu.ca and Chuanxi Ma; chuanxi.ma@aliyun.com

Received 13 February 2014; Accepted 19 March 2014; Published 10 April 2014

Academic Editor: Wujun Ma

Copyright (c) 2014 Hongqi Si et al. This is an open access article distributed under the Creative Commons Attribution License, which permits unrestricted use, distribution, and reproduction in any medium, provided the original work is properly cited.

Low-molecular-weight glutenin subunits (LMW-GS) are of great importance in processing quality and participate in the formation of polymers in wheat. In this study, eight new LMW-GS alleles were isolated from Chinese wheat landraces (Triticum aestivum L.) and designated as Glu-A3-1a, Glu-A3-1b, Glu-B3-1a, Glu-B3-1b, Glu-B3-1c, Glu-D3-1a, Glu-D3-1b, and Glu-D3-1c, which were located at the Glu-A3, Glu-B3, and Glu-D3 loci, respectively. Based on the proteins encoded, the number of deduced amino acids of Glu-B3 alleles was approximately 50 more than those of Glu-A3 and Glu-D3 alleles. The first cysteine of Glu-A3 and Glu-D3 alleles was located at the N-terminal domain, while that of $G l u-B 3$ alleles was found in the repetitive domain, which may lead to the different functioning in forming disulfide bonds. All the eight genes were LMW-m types and the new allele of Glu-B3-1a which had nine cysteine residues may be the desirable LMW-GS gene for improving bread-making quality.

\section{Introduction}

Wheat dough possesses unique viscoelastic properties determined by the structure and interaction of storage proteins in making bread and noodles [1]. Wheat storage proteins are mainly composed of monomeric gliadins and polymeric glutenins [2, 3], and these glutenins are divided into the low-molecular-weight glutenin subunits (LMW-GS) and the high-molecular-weight glutenin subunits (HMWGS) according to their electrophoretic mobility in sodium dodecyl sulfate-polyacrylamide gel electrophoresis (SDSPAGE) [4]. The HMW-GS have been recognized as the major determinants of dough and gluten properties [5], but LMWGS also play an important role in determining wheat dough's viscoelastic properties [6].

The LMW-GS genes are encoded by Glu-A3, Glu-B3, and Glu-D3 loci on the short arms of chromosomes 1A, 1B, and $1 \mathrm{D}$, respectively, in hexaploid wheat [7]. Allelic variation in LMW-GS is generally accepted to have an important effect on wheat processing quality [8]. Glu-A3a, Glu-B3d, and Glu$D 3 a$ have a better effect on dough strength than other alleles at the Glu-3 loci. The effects of Glu-A3d, Glu-B3i, Glu-A3d, and Glu-B3d contribute most to dough extensibility and Zeleny sedimentation volume, while Glu-D3 loci do not have a significant effect on either [9]. According to He et al. [10], noodle quality is decided by the protein subunits of Glu-A3d and $G l u-B 3 d$, and Glu-A3d is significantly more important in this process than other alleles. Si et al. [11] reported that $G l u-B 3 b, G l u-B 3 g$, and $G l u-B 3 h$ significantly heightened the SDS sedimentation volume, while Glu-B3a, Glu-B3c, and Glu$B 3 j$ significantly lowered the SDS sedimentation volume. So far, no consistent conclusion has been reached regarding the influence of LMW-GS allelic variation on wheat processing quality, perhaps due to the different materials used, and the interaction between genotypes and the environment.

Although the mobility of many LMW-GS subunits is very similar and sometimes overlapped with each other in SDSPAGE, a lot of researches have recently been conducted on 
TABLE 1: Comparison of nucleotide sequences of the eight cloned genes.

\begin{tabular}{|c|c|c|c|c|c|}
\hline LMW-GS genes & Upstream & CDS & Total length & $\begin{array}{c}\text { Deduced } \\
\text { amino acids }\end{array}$ & $\begin{array}{l}\text { Putative transcription binding sites in the } \\
\text { upstream region }\end{array}$ \\
\hline Glu-A3-1a & $195 \mathrm{bp}$ & $894 \mathrm{bp}$ & 1089 bp & 298 & CAAT-box, TATA-box, ARE, and MRE \\
\hline Glu-A3-1b & $195 \mathrm{bp}$ & $894 \mathrm{bp}$ & $1089 \mathrm{bp}$ & 298 & CAAT-box, TATA-box, ARE, and MRE \\
\hline Glu-B3-1a & $317 \mathrm{bp}$ & 1053 bp & 1370 bp & 351 & $\begin{array}{c}\text { CAAT-box, TATA-box, and } \\
\text { Prolamin-box }\end{array}$ \\
\hline Glu-B3-1b & $317 \mathrm{bp}$ & $1044 \mathrm{bp}$ & $1361 b p$ & 348 & $\begin{array}{l}\text { CAAT-box, TATA-box, and } \\
\text { Prolamin-box }\end{array}$ \\
\hline Glu-B3-1c & $317 \mathrm{bp}$ & $1050 \mathrm{bp}$ & 1367 bp & 350 & $\begin{array}{l}\text { CAAT-box, TATA-box, and } \\
\text { Prolamin-box }\end{array}$ \\
\hline Glu-D3-1a & $593 \mathrm{bp}$ & $921 b p$ & 1591 bp & 307 & $\begin{array}{l}\text { CAAT-box, TATA-box, and } \\
\text { Prolamin-box }\end{array}$ \\
\hline Glu-D3-1b & $605 \mathrm{bp}$ & $921 b p$ & $1603 b p$ & 307 & $\begin{array}{l}\text { CAAT-box, TATA-box, and } \\
\text { Prolamin-box }\end{array}$ \\
\hline Glu-D3-1c & $605 \mathrm{bp}$ & $912 b p$ & $1594 \mathrm{bp}$ & 306 & $\begin{array}{l}\text { CAAT-box, TATA-box, and } \\
\text { Prolamin-box }\end{array}$ \\
\hline
\end{tabular}

LMW-GS genes by allelic-specific polymerase chain reaction (PCR) in common wheat and related species [12-14], which lead to a better understanding of the function, structure, and diversity of LMW-GS.

The landraces possess many useful traits that have been lost in modern cultivars. The phenological, morphological, physiological, and quality traits in landraces are genetically diverse [15]. Although more than 15 LMW-GS genes have been found so far in wheat [16], further studies of the diversity of these LMW-GS genes and cloning of new and rare alleles are interesting and challenging. In this study, we isolated and characterized eight new alleles located at Glu-A3, GluB3, and Glu-D3 loci from landraces for which no LMW-GS genes have been previously detected by the corresponding molecular markers [17-19].

\section{Materials and Methods}

2.1. Plant Materials. The landraces Jiangdongmen, Daqingmang, Hongjinbaoyin, Dabaimai, Hongmangzi, Hongdougou, and Baimangmai used in this study were kindly provided by the National Gene Bank of China, Institute of Crop Science, CAAS, China. In our previous research, none of the LMW-GS genes were detected in the varieties Daqingmang and Hongjinbaoyin using the PCR markers for Glu-A3 [17] alleles, the Glu-B3 [18] alleles from the varieties Hongdougou, Dabaimai, and Hongmangzi, or the Glu-D3 [19] alleles from the varieties Jiangdongmen, Daqingmang, and Baimangmai. To determine whether the genes at the Glu-A3, Glu-B3, and Glu-D3 loci corresponding to the above varieties are missing or whether it is a novel gene, we used locus-specific primers to amplify the LMW-GS genes specifically for the Glu-A3, Glu-B3, and Glu-D3 loci.

2.2. Genomic DNA Extraction and PCR Amplification. Genomic DNA was isolated from single dry seeds according to the procedure of SDS-phenol-chloroform with minor modification. Six locus-specific primer sets,
Glua3f1/Glua3r2 (R: GTACGCTTTTGTAGCTTGTGC, F: GATGCCAACGCCTAATGGCACAC) [17], 5/7 (R: TCCTGAGAAGTGCATGACATG, F: GTAGGCACCAACTCCGGTGC) [20], and 3/4 (R: TTGTAGAAACTGCCATCCTT, F: GTCACCGCTGCATCGACATA) [20], were used for amplifying LMW-GS genes at the Glu-A3 locus on chromosome $1 \mathrm{~A}$ and the Glu-B3 and Glu-D3 loci on chromosomes $1 \mathrm{~B}$ and $1 \mathrm{D}$, respectively. The locusspecific primers were synthesized by Shanghai Sangon Biological Engineering \& Technology and Service Ltd. (http://www.sangon.com/). PCR amplification was performed using Ex Taq DNA polymerase (0.5 U, TaKaRa, Shiga, Japan) in $10 \mu \mathrm{L}$ of $1 \mathrm{x}$ PCR buffer (comprising $2 \mathrm{mM}$ $\mathrm{MgCl}_{2}$; TaKaRa) containing $50 \mathrm{ng}$ genomic DNA, $0.1 \mathrm{mM}$ dNTP, and $20 \mu \mathrm{M}$ of each primer. The PCR conditions were $94^{\circ} \mathrm{C}$ for $5 \mathrm{~min}$ followed by 38 cycles at $94^{\circ} \mathrm{C}$ for $1 \mathrm{~min}$ (or $35 \mathrm{~s}$ for primer pair $3 / 4$ at $52^{\circ} \mathrm{C}, 5 / 7$ at $54^{\circ} \mathrm{C}$, and Glua3f1/Glua3r2 at $59^{\circ} \mathrm{C}$ ), followed by $72^{\circ} \mathrm{C}$ for $90 \mathrm{~s}$ and a final extension at $72^{\circ} \mathrm{C}$ for $10 \mathrm{~min}$.

2.3. DNA Cloning and Sequencing of LMW-GS Genes. The PCR products were separated using $1.2 \%$ agarose gels and the expected fragments were isolated from the gels using an EasyPure Quick Gel Extraction Kit (TransGen, Beijing, China). The isolated PCR products were cloned into the pMD18T Simple Vector (TaKaRa) and transformed into E. coli Competent Cells DH5 $\alpha$ (TaKaRa). The positive colonies were verified using M13 universal primers, and the selected clones were sequenced by Shanghai Sangon Biological Engineering \& Technology and Service Ltd. Each PCR and sequencing analysis was repeated at least three times to avoid technical errors.

2.4. Accession Numbers. The LMW-GS gene sequences identified from Jiangdongmen, Daqingmang, Hongjinbaoyin, Dabaimai, Hongmangzi, Hongdougou, and Baimangmai were deposited in GenBank under accession numbers KF020658-KF020665. KF020658 and KF020659 were cloned 
TABLE 2: Sequence identities of the eight new LMW-GS alleles to the previously reported Glu-3 genes.

\begin{tabular}{|c|c|c|c|c|c|c|c|c|c|}
\hline \multirow{2}{*}{ LMW-GS alleles } & \multicolumn{3}{|c|}{ Glu-A3 gene accession number } & \multicolumn{3}{|c|}{ Glu-B3 gene accession number } & \multicolumn{3}{|c|}{ Glu-D3 gene accession number } \\
\hline & FJ549946 & FJ549937 & FJ549938 & DQ630441 & EU369729 & EU369730 & DQ357054 & DQ357055 & EU189094 \\
\hline Glu-A3-1a & 93 & 92 & 92 & 84 & 84 & 84 & 87 & 87 & 87 \\
\hline Glu-A3-1b & 93 & 92 & 91 & 83 & 83 & 83 & 86 & 86 & 87 \\
\hline Glu-B3-1a & 85 & 85 & 85 & 95 & 84 & 84 & 83 & 83 & 83 \\
\hline Glu-B3-1b & $\mathrm{N}$ & 85 & 86 & 99 & 85 & 85 & 84 & 84 & 85 \\
\hline Glu-B3-1c & $\mathrm{N}$ & 85 & 86 & 99 & 85 & 85 & 83 & 83 & 84 \\
\hline Glu-D3-1a & 87 & 88 & 88 & 88 & 85 & 85 & 95 & 95 & 94 \\
\hline Glu-D3-1b & 86 & 87 & 87 & 83 & 82 & 82 & 99 & 99 & 99 \\
\hline Glu-D3-1c & 87 & 87 & 87 & 84 & 82 & 82 & 99 & 99 & 99 \\
\hline
\end{tabular}

Note: $\mathrm{N}$ means that no highly similar sequences were found using BLAST tools.

using Glu-A3 locus-specific primers from Daqingmang and Hongjinbaoyin, designated as Glu-A3-1a and Glu-A3$1 b$, respectively. The sequences KF020660-KF020662 were cloned using Glu-B3 locus-specific primers from Hongdougou, Dabaimai, and Hongmangzi, designated as Glu-B3$1 a$, Glu-B3-1b, and Glu-B3-1c, respectively, and KF020663KF020665 were cloned using Glu-D3 locus-specific primers from Jiangdongmen, Daqingmang, and Baimangmai, designated as Glu-D3-1a, Glu-D3-1b, and Glu-D3-1c, respectively.

2.5. LMW-GS Gene Analysis. Sequence analysis and characterization were performed using DNAMAN software (http://www.lynnon.com/), BLAST tools at NCBI (http://blast.ncbi.nlm.nih.gov/Blast.cgi/), and the PlantCare database (http://bioinformatics.psb.ugent.be/webtools/plantcare/html/). The nomenclature of the LMW-GS genes followed the "Catalogue of Gene Symbols for Wheat" at http://wheat.pw.usda.gov/ggpages/wgc/98//.

\section{Results and Discussion}

3.1. Basic Characteristics of the LMW-GS Alleles Identified in This Study. Eight novel LMW-GS alleles with no intron were obtained in this study (see Figure S1 in Supplementary Material available online at http://dx.doi.org/10.1155/2014/371045/). Their sequences were submitted to GenBank with the accession numbers KF020658-KF020665 and designated as Glu-A3-1a, GluA3-1b, Glu-B3-1a, Glu-B3-1b, Glu-B3-1c, Glu-D3-1a, Glu$D 3-1 b$, and Glu-D3-1c, following the nomenclature rules at http://wheat.pw.usda.gov/ggpages/wgc/98//. Glu-A3-1a and Glu-A3-1b had the same size of $1089 \mathrm{bp}$ and could be translated into 298 amino acids. The nucleotide and deduced amino acid sequences of the other six genes were varied with 1361-1603 bp and 306-351 residues (Table 1). The upstream nucleotide sequences of the cloned genes were searched for in the PlantCare database to analyze the characteristics of the promoter sequences. The eight genes all contained CAAT-boxes and TATA-boxes. Glu-B3-1a, Glu-B3-1b, GluB3-1c, Glu-D3-1a, Glu-D3-1b, and Glu-D3-1c contained a Prolamin-box in the upstream sequence (Table 1). All eight genes from landraces in our study belonged to the LMW-m type since their first amino acid at the $\mathrm{N}$-terminal was methionine.

3.2. Nucleotide Comparison Analysis of the LMW-GS Alleles within the Glu-3 Loci. To more accurately compare the differences between LMW-GS genes at the Glu-3 loci, we used BLAST tools to find the sequences most similar to the eight genes obtained in this study. Nine Glu-3 genes deposited in GenBank were selected for multiple sequence alignment and included FJ549937, FJ549938, and FJ549946 located at the Glu-A3 locus; EU369729, EU369730, and DQ630441 at the Glu-B3 locus; and DQ357054, DQ357055, and EU189094 at the Glu-D3 locus. Based on the results of these alignments (Table 2), of the eight genes isolated in this study, Glu-A3$1 a$, and Glu-A3-1b were found to be new alleles at the Glu-A3 locus; Glu-B3-1a, Glu-B3-1b, and Glu-B3-1c were new alleles at the Glu-B3 locus; and Glu-D3-1a, Glu-D3-1b, and Glu-D3$1 c$ were new alleles at the Glu-D3 locus.

3.3. Deduced Proteins Comparison Analysis of the LMWGS Alleles within the Glu-3 Loci. The deduced amino acid sequences of the eight genes comprised four structural regions, including a signal peptide of 20 amino acids, a conserved $\mathrm{N}$-terminal region of 13 amino acids, a diverse repetitive domain, and a C-terminal domain, suggesting that the eight genes conformed to the typical molecular characteristics of LMW-GS (Supplementary Material, Figure S2). We compared the alleles within the Glu-3 loci and found that isoleucine was at the sixth position of the signal peptide in the allele located at Glu-B3 locus, while valine was at the Glu-A3 and Glu-D3 loci (Table 3), which might result from the substitution of ATC for GTC (Supplementary Material, Figure S1). The eleventh position of the N-terminal at the Glu$A 3$ and Glu-D3 loci was arginine, while lysine filled the same position at the Glu-B3 locus (Table 3), which may be the result of an AGA $\rightarrow$ AAA transversion (Supplementary Material, Figure S1).

Eight cysteine residues were found in Glu-A3-1a, Glu-A31b, Glu-B3-1b, Glu-B3-1c, Glu-D3-1a, Glu-D3-1b, and Glu-D3$1 c$, while Glu-B3-1a had nine. By comparing the Glu-3 loci alleles, the locations of the first and seventh cysteine were found to be varied. As shown in Figure S2 (Supplementary Material) and Table 3, the first cysteine of the Glu-A3 and 
TABLE 3: Comparison of the deduced amino acid sequences for genes isolated in this study and data from GenBank.

\begin{tabular}{|c|c|c|c|c|c|c|c|c|c|c|c|c|c|c|}
\hline & & Sig. & \multicolumn{2}{|c|}{ N-ter. } & \multicolumn{2}{|c|}{ Rep. } & \multicolumn{8}{|c|}{ C-ter. } \\
\hline \multirow{5}{*}{ Glu-A3 } & FJ549937 & $\mathrm{V}$ & $\mathrm{C}$ & $\mathrm{R}$ & & & $\mathrm{C}$ & $\mathrm{C}$ & $\mathrm{C}$ & $\mathrm{CC}$ & & $\mathrm{C}$ & & $\mathrm{C}$ \\
\hline & FJ549938 & $\mathrm{V}$ & $\mathrm{C}$ & $\mathrm{R}$ & & & $\mathrm{C}$ & $\mathrm{C}$ & $\mathrm{C}$ & $\mathrm{CC}$ & & $\mathrm{C}$ & & $\mathrm{C}$ \\
\hline & FJ549946 & V & $\mathrm{C}$ & $\mathrm{R}$ & & & $\mathrm{C}$ & $\mathrm{C}$ & $\mathrm{C}$ & $\mathrm{CC}$ & & $\mathrm{C}$ & & $\mathrm{C}$ \\
\hline & Glu-A3-1a & $\mathrm{V}$ & $\mathrm{C}$ & $\mathrm{R}$ & & & $\mathrm{C}$ & $\mathrm{C}$ & $\mathrm{C}$ & $\mathrm{CC}$ & & $\mathrm{C}$ & & $\mathrm{C}$ \\
\hline & Glu-A3-1b & $\mathrm{V}$ & $\mathrm{C}$ & $\mathrm{R}$ & & & $\mathrm{C}$ & $\mathrm{C}$ & $\mathrm{C}$ & $\mathrm{CC}$ & & $\mathrm{C}$ & & $\mathrm{C}$ \\
\hline \multirow{6}{*}{ Glu-B3 } & EU369729 & I & & $\mathrm{K}$ & & C & $\mathrm{C}$ & $\mathrm{C}$ & $\mathrm{C}$ & CC & & $\mathrm{C}$ & & $\mathrm{C}$ \\
\hline & EU369730 & I & & $\mathrm{K}$ & & $\mathrm{C}$ & $\mathrm{C}$ & $\mathrm{C}$ & $\mathrm{C}$ & $\mathrm{CC}$ & & $\mathrm{C}$ & & $\mathrm{C}$ \\
\hline & DQ630441 & I & & $\mathrm{K}$ & $\mathrm{C}$ & & $\mathrm{C}$ & $\mathrm{C}$ & $\mathrm{C}$ & $\mathrm{CC}$ & & $\mathrm{C}$ & & $\mathrm{C}$ \\
\hline & Glu-B3-1a & I & & K & $\mathrm{C}$ & & $\mathrm{C}$ & $\mathrm{C}$ & $\mathrm{C}$ & $\mathrm{CC}$ & & $\mathrm{C}$ & $\mathrm{C}$ & $\mathrm{C}$ \\
\hline & Glu-B3-1b & I & & $\mathrm{K}$ & $\mathrm{C}$ & & $\mathrm{C}$ & $\mathrm{C}$ & $\mathrm{C}$ & $\mathrm{CC}$ & & $\mathrm{C}$ & & $\mathrm{C}$ \\
\hline & Glu-B3-1c & I & & $\mathrm{K}$ & $\mathrm{C}$ & & $\mathrm{C}$ & $\mathrm{C}$ & $\mathrm{C}$ & $\mathrm{CC}$ & & $\mathrm{C}$ & & $\mathrm{C}$ \\
\hline \multirow{6}{*}{ Glu-D3 } & DQ357054 & $\mathrm{V}$ & $\mathrm{C}$ & $\mathrm{R}$ & & & $\mathrm{C}$ & $\mathrm{C}$ & $\mathrm{C}$ & $\mathrm{CC}$ & $\mathrm{C}$ & & & $\mathrm{C}$ \\
\hline & DQ357055 & $\mathrm{V}$ & $\mathrm{C}$ & $\mathrm{R}$ & & & $\mathrm{C}$ & $\mathrm{C}$ & $\mathrm{C}$ & $\mathrm{CC}$ & $\mathrm{C}$ & & & $\mathrm{C}$ \\
\hline & EU189094 & $\mathrm{V}$ & $\mathrm{C}$ & $\mathrm{R}$ & & & $\mathrm{C}$ & $\mathrm{C}$ & $\mathrm{C}$ & $\mathrm{CC}$ & $\mathrm{C}$ & & & $\mathrm{C}$ \\
\hline & Glu-D3-1a & $\mathrm{V}$ & $\mathrm{C}$ & $\mathrm{R}$ & & & $\mathrm{C}$ & $\mathrm{C}$ & $\mathrm{C}$ & $\mathrm{CC}$ & $\mathrm{C}$ & & & $\mathrm{C}$ \\
\hline & Glu-D3-1b & $\mathrm{V}$ & $\mathrm{C}$ & $\mathrm{R}$ & & & $\mathrm{C}$ & $\mathrm{C}$ & $\mathrm{C}$ & $\mathrm{CC}$ & $\mathrm{C}$ & & & $\mathrm{C}$ \\
\hline & Glu-D3-1c & $\mathrm{V}$ & $\mathrm{C}$ & $\mathrm{R}$ & & & $\mathrm{C}$ & $\mathrm{C}$ & $\mathrm{C}$ & $\mathrm{CC}$ & $\mathrm{C}$ & & & $\mathrm{C}$ \\
\hline
\end{tabular}

The accession numbers are as follows: FJ549937, FJ549938, and FJ549946 are genes at the Glu-A3 locus; EU369729, EU369730, and DQ630441 are genes at the Glu-B3 locus; and DQ357054, DQ357055, and EU189094 are genes at Glu-D3 locus. I, V, R, K, and C represent isoleucine, valine, arginine, lysine, and cysteine, respectively.

Glu-D3 alleles was located at the fifth position of the Nterminal domain, whereas the first cysteine of the Glu-B3 alleles was found at the 46th position of the deduced amino acid sequences in the repetitive domain. The seventh cysteine at the Glu-D3 alleles was located 16 amino acids higher up than that at the Glu-A3 and Glu-B3 alleles. In particular, the extra cysteine of allele Glu-B3-1a was found at the 321st position of the amino acid sequence.

Usually the first and seventh cysteine residues participate in forming the intermolecular disulfide bond, while the remaining residues participate in the formation of intramolecular disulfide bonds [21]. Disulfide bonds have an important influence on determining the properties and structure of wheat gluten proteins [22]. The first cysteine at the Glu-B3 allele was in the repetitive domain, however, the first cysteine at Glu-A3 and Glu-D3 alleles were in the Nterminal. The positions of the seventh cysteine residue at the $G l u-D 3$ alleles were also different from the Glu-A3 and Glu-B3 alleles. The LMW-GS gene, which had nine cysteine residues, resulted in desirable processing quality [20]; therefore, the new allele of Glu-B3-1a may be the desirable LMW-GS gene for improving bread-making quality because the extra cysteine residue could form more disulfide bonds than other alleles during the development of glutenin macropolymer.

Insertions/deletions often appeared within the repetitive domain. The length variation of the LMW-GS genes was mainly due to the numbers of repeat motifs, which ranged from 12 to 25 in the repetitive domain. The repeat motif is shown in Table 4. Two long insertions were present in the Glu-B3 sequences, that is, 18 amino acid insertions at positions 44-61 and eight amino acid insertions at positions 81-88. The repetitive region was composed of a representative repeat motif $\mathrm{P}_{1-2} \mathrm{FP} / \mathrm{SQ}_{2-6}$, of which the number would have an impact on changes in the length of the protein [23]. The length of the diverse repetitive domain of Glu-B3 alleles was longer than those of Glu-A3 and Glu-D3 alleles since more insertions occurred in this domain. Masci et al. [24] indicated that a $42 \mathrm{~K}$ LMW-GS would have a good processing quality due to its large repeat domain. The repeat domain through intermolecular interactions between large numbers of glutamine side chains, which are both good hydrogen bond donors and acceptors, may prove useful in increasing the viscosity and elasticity of wheat dough [24]. More repeat motifs in the repetitive domain would lead to a better flour quality [25]. Based on Figure S2 (Supplementary Material), the sequences at the Glu-B3 locus had 50 more deduced amino acids than those at Glu-A3 and Glu-D3 loci. Therefore, genes at the Glu-B3 locus are more desirable than those at the Glu-A3 and Glu-D3 loci.

\section{Conclusion}

This study showed that, of the eight new Glu-3 alleles added to the LMW-GS gene family, Glu-B3-1a had nine cysteine residues and the others had eight. The first cysteine of Glu$A 3$ and Glu-D3 alleles was found in the N-terminal domain, while it was located at the repetitive domain of Glu-B3 alleles. The LMW-GS allele of Glu-B3-1a can be used as candidate gene for improving bread-making quality because it can form more disulfide bonds.

\section{Conflict of Interests}

All authors declare that they have no conflict of interests regarding the publication of this paper. 


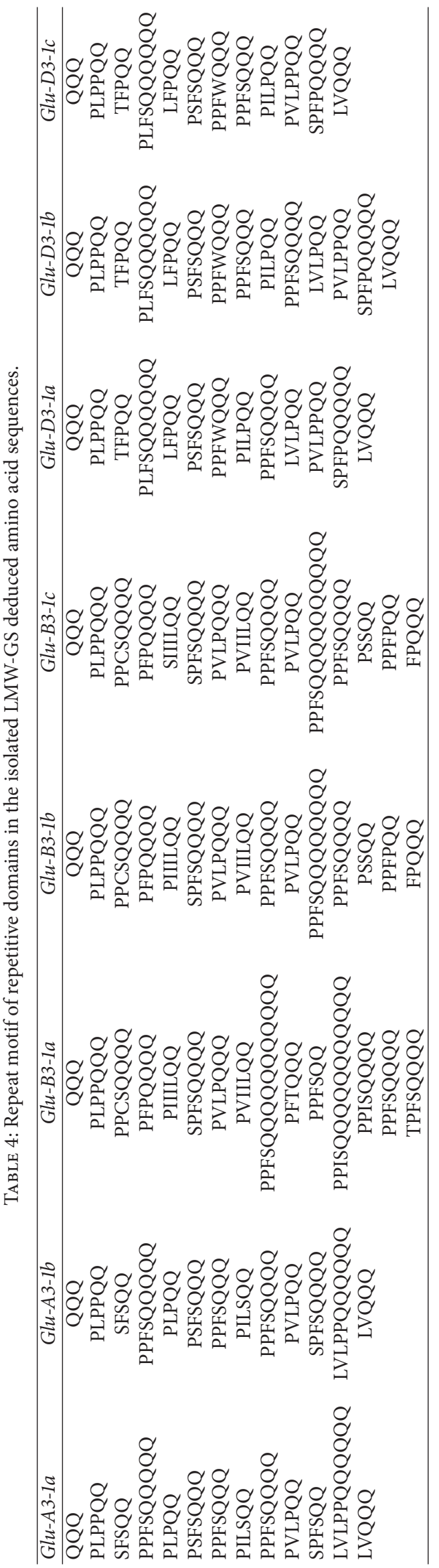




\section{Acknowledgments}

This work was supported by Grants from the National Key Technologies R\&D Program (2011BAD35B03), the China Agriculture Research System (CARS-03), the National 863 Program (2012AA101105), the Anhui Provincial Science and Technology Program (1201a0301010), and the Collaborative Innovation Center of Food Crops in Anhui Province.

\section{References}

[1] T. Dutta, H. Kaur, S. Singh et al., "Developmental changes in storage proteins and peptidyl prolyl cis-trans isomerase activity in grains of different wheat cultivars," Food Chemistry, vol. 128, no. 2, pp. 450-457, 2011.

[2] P. Chen, R. Li, R. Y. Zhou, E. Zhiguo, and G. Y. He, "Cloning and characterization of novel low molecular weight glutenin subunit genes from two Aegilops species with the C and D genomes," Genetic Resources and Crop Evolution, vol. 57, no. 6, pp. 881-890, 2010.

[3] X. An, Q. Zhang, Y. Yan et al., "Cloning and molecular characterization of three novel LMW-i glutenin subunit genes from cultivated einkorn (Triticum monococcum L.)," Theoretical and Applied Genetics, vol. 113, no. 3, pp. 383-395, 2006.

[4] H. Tanaka, S. Toyoda, and H. Tsujimoto, "Diversity of lowmolecular-weight glutenin subunit genes in Asian common wheat (Triticum aestivum L.)," Breeding Science, vol. 55, no. 3, pp. 349-354, 2005.

[5] Y. Popineau, M. Cornec, J. Lefebvre, and B. Marchylo, "Influence of high $\mathrm{Mr}$ glutenin is subunits on glutenin polymers and rheological properties of glutens and gluten subfractions of near-isogenic lines of wheat sicco," Journal of Cereal Science, vol. 19, no. 3, pp. 231-241, 1994.

[6] X. F. Zhang, D. C. Liu, W. Jiang et al., "PCR-based isolation and identification of full-length low-molecular-weight glutenin subunit genes in bread wheat (Triticum aestivum L.)," Theoretical and Applied Genetics, vol. 123, no. 8, pp. 1293-1305, 2011.

[7] N. K. Singh and K. W. Shepherd, "Linkage mapping of genes controlling endosperm storage proteins in wheat," Theoretical and Applied Genetics, vol. 75, no. 4, pp. 628-641, 1988.

[8] C. Luo, W. B. Griffin, G. Branlard, and D. L. McNeil, "Comparison of low- and high molecular-weight wheat glutenin allele effects on flour quality," Theoretical and Applied Genetics, vol. 102, no. 6-7, pp. 1088-1098, 2001.

[9] G. Branlard, M. Dardevet, R. Saccomano, F. Lagoutte, and J. Gourdon, "Genetic diversity of wheat storage proteins and bread wheat quality," Euphytica, vol. 119, no. 1-2, pp. 59-67, 2001.

[10] Z. H. He, L. Liu, X. C. Xia, J. J. Liu, and R. J. Pena, "Composition of HMW and LMW glutenin subunits and their effects on dough properties, pan bread, and noodle quality of Chinese bread wheats," Cereal Chemistry, vol. 82, no. 4, pp. 345-350, 2005.

[11] H. Si, M. Zhao, F. He, and C. Ma, "Effect of Glu-B3 allelic variation on sodium dodecyl sulfate sedimentation volume in common wheat (Triticum aestivum L.)," The Scientific World Journal, vol. 2013, Article ID 848549, 5 pages, 2013.

[12] Q. X. Lan, B. Feng, Z. M. Xu, G. J. Zhao, and T. Wang, "Molecular cloning and characterization of five novel low molecular weight glutenin subunit genes from Tibetan wheat landraces (Triticum aestivum L.)," Genetic Resources and Crop Evolution, vol. 60, no. 2, pp. 799-806, 2013.
[13] S. L. Wang, D. Chen, G. F. Guo et al., "Molecular Characterization of LMW-GS Genes from C, N, U and $\mathrm{S}^{\mathrm{s}}$ genomes among Aegilops Species," Cereal Research Communications, vol. 40, no. 4, pp. 542-551, 2012.

[14] S. L. Wang, K. Wang, G. X. Chen et al., "Molecular characterization of LMW-GS genes in Brachypodium distachyon L. reveals highly conserved Glu-3 loci in Triticum and related species," BMC Plant Biology, vol. 12, article 221, 2012.

[15] A. Cherdouh, D. Khelifi, J. M. Carrillo, and M. T. NietoTaladriz, "The high and low molecular weight glutenin subunit polymorphism of Algerian durum wheat landraces and old cultivars," Plant Breeding, vol. 124, no. 4, pp. 338-342, 2005.

[16] X. Zhang, D. Liu, J. Zhang et al., "Novel insights into the composition, variation, organization, and expression of the lowmolecular-weight glutenin subunit gene family in common wheat," Journal of Experimental Botany, vol. 64, no. 7, pp. 20272040, 2013.

[17] W. Zhang, M. C. Gianibelli, L. R. Rampling, and K. R. Gale, "Characterisation and marker development for low molecular weight glutenin genes from Glu-A3 alleles of bread wheat (Triticum aestivum L)," Theoretical and Applied Genetics, vol. 108, no. 7, pp. 1409-1419, 2004.

[18] L. H. Wang, X. L. Zhao, Z. H. He et al., "Characterization of low-molecular-weight glutenin subunit Glu-B3 genes and development of STS markers in common wheat (Triticum aestivum L.)," Theoretical and Applied Genetics, vol. 118, no. 3, pp. 525-539, 2009.

[19] X. L. Zhao, X. C. Xia, Z. H. He et al., "Novel DNA variations to characterize low molecular weight glutenin Glu-D3 genes and develop STS markers in common wheat," Theoretical and Applied Genetics, vol. 114, no. 3, pp. 451-460, 2007.

[20] H. X. Zhao, A. G. Guo, S. W. Hu et al., "Development of primers specific for LMW-GS genes at Glu-D3 and Glu-B3 loci and PCR amplification," Acta Agronomica Sinica, vol. 30, no. 2, pp. 126130, 2004.

[21] E. J. L. Lew, D. D. Kuzmicky, and D. D. Kasarda, "Characterization of low molecular weight glutenin subunits by reversedphase high-performance liquid chromatography, sodium dodecyl sulfate-polyacrylamide gel electrophoresis, and N-terminal amino acid sequencing," Cereal Chemistry, vol. 69, no. 5, pp. 508-515, 1992.

[22] P. R. Shewry and A. S. Tatham, "Disulphide bonds in wheat gluten proteins," Journal of Cereal Science, vol. 25, no. 25, pp. 207-227, 1997.

[23] B. G. Cassidy, J. Dvorak, and O. D. Anderson, "The wheat lowmolecular-weight glutenin genes: characterization of six new genes and progress in understanding gene family structure," Theoretical and Applied Genetics, vol. 96, no. 6-7, pp. 743-750, 1998.

[24] S. Masci, R. D’Ovidio, D. Lafiandra, and D. D. Kasarda, "A 1Bcoded low-molecular-weight glutenin subunit associated with quality in durum wheats shows strong similarity to a subunit present in some bread wheat cultivars," Theoretical and Applied Genetics, vol. 100, no. 3-4, pp. 396-400, 2000.

[25] S. Masci, R. D’Ovidio, D. Lafiandra, and D. D. Kasarda, "Characterization of a low-molecular-weight glutenin subunit gene from bread wheat and the corresponding protein that represents a major subunit of the glutenin polymer," Plant Physiology, vol. 118 , no. 4, pp. 1147-1158, 1998. 


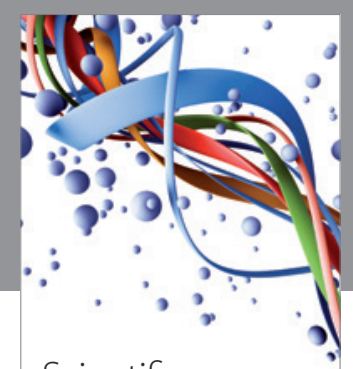

Scientifica
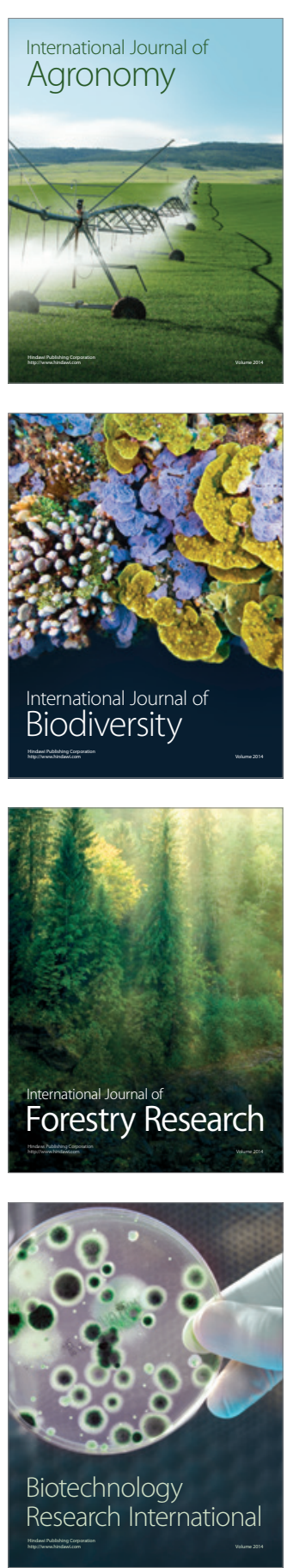
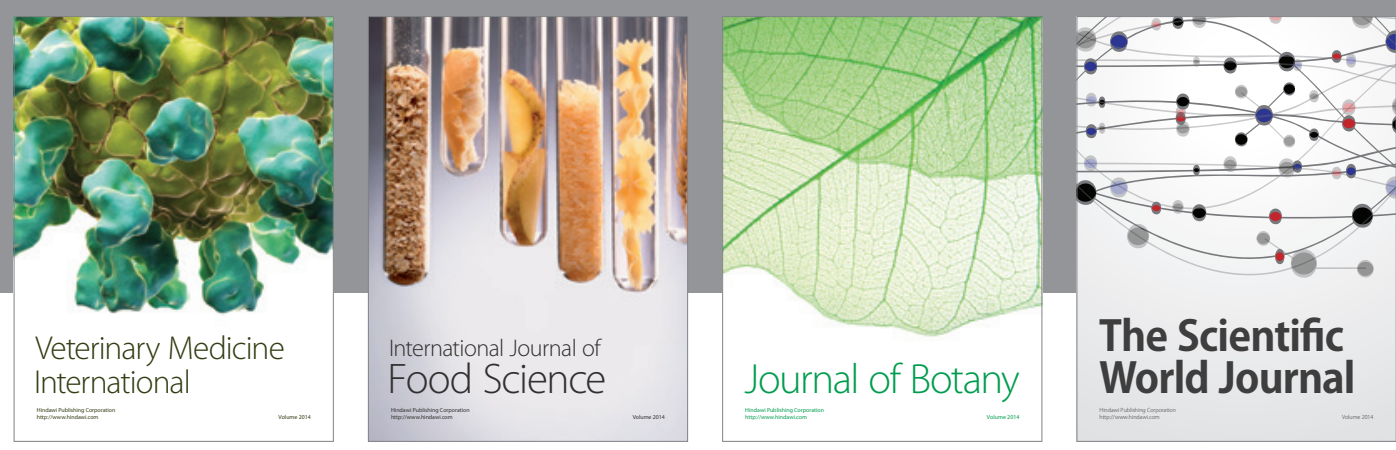

The Scientific World Journal
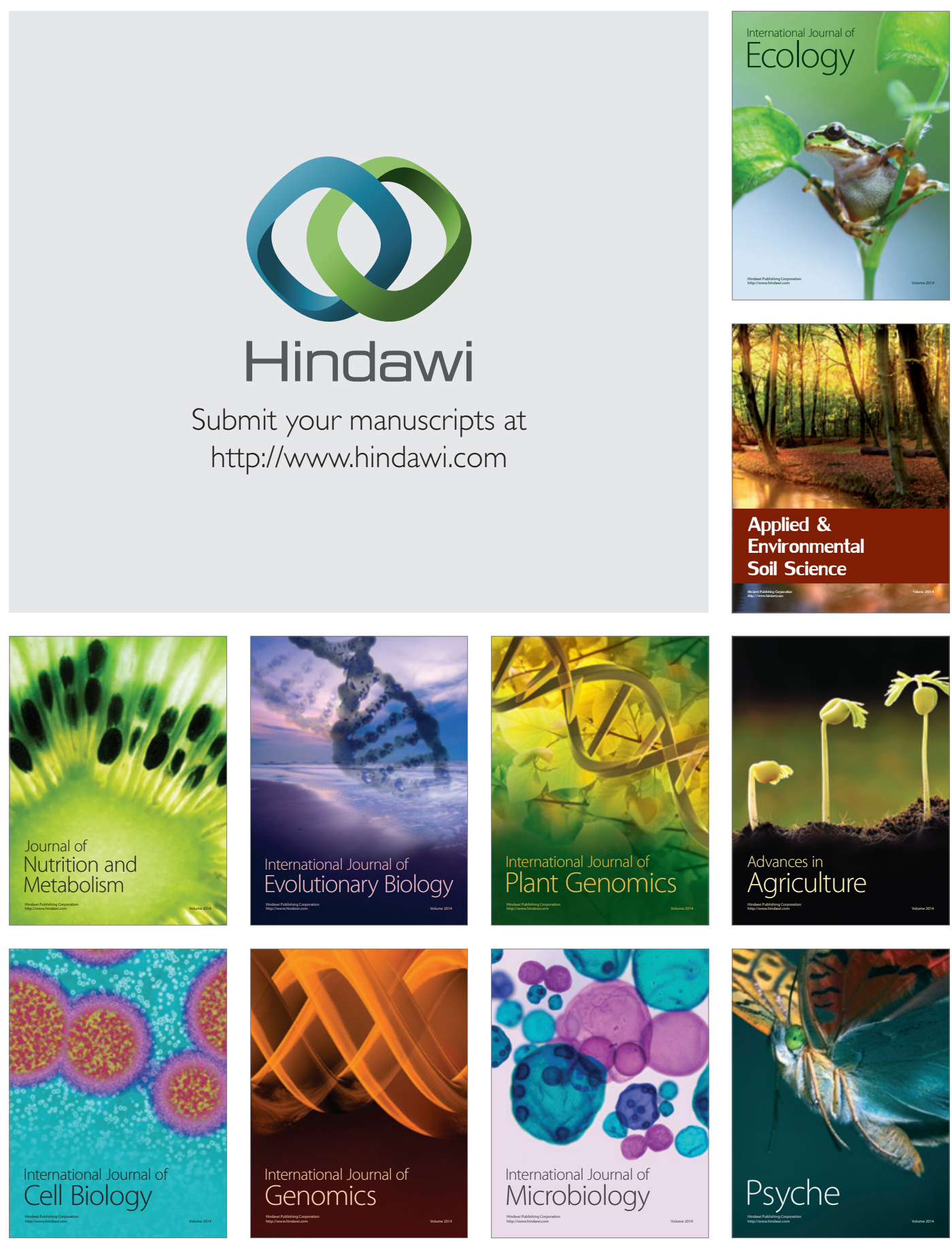